\title{
Googling your genes: personal genomics and the discourse of citizen bioscience in the network age ${ }^{1}$
}

\author{
Marina Levina
}

\begin{abstract}
In this essay, I argue that the rise of personal genomics is technologically, economically, and most importantly, discursively tied to the rise of network subjectivity, an imperative of which is an understanding of self as always already a subject in the network. I illustrate how personal genomics takes full advantage of social media technology and network subjectivity to advertise a new way of doing research that emphasizes collaboration between researchers and its members. Sharing one's genetic information is considered to be an act of citizenship, precisely because it is good for the network. Here members are encouraged to think of themselves as dividuals, or nodes, in the network and their actions acquire value based on that imperative. Therefore, citizen bioscience is intricately tied, both in discourse and practices, to the growth of the network in the age of new media.
\end{abstract}

\section{Context}

November 2007 witnessed the launch of a new Internet startup: 23 andMe. Advertised as the first personal genome service, 23andMe offers to unlock the secrets of your own DNA:

\begin{abstract}
Welcome to 23 andMe, a web-based service that helps you read and understand your DNA. After providing a saliva sample using an at-home kit, you can use our interactive tools to shed new light on your distant ancestors, your close family and most of all, yourself. ${ }^{2}$
\end{abstract}

Offering various services such as the gene journal (what do your genes say about you?), ancestry search (who were your ancient ancestors?), family inheritance (do you have your mother's sense of taste?), and genome labs (would you like to search your genome?) 23andMe caused a splash at least partially because of its affiliation with Google. It is, however, just one of the services in the growing personal genomics industry. Enabled by the increasingly cheaper genome sequencing technology and the rise of human variation genomics, ${ }^{3}$ personal genomics emphasizes placing control over genetic information into consumers' hands. In turn, 23 andMe and the burgeoning field of personal genomics have been branded the newest, potentially revolutionary industry of our decade. ${ }^{4}$ Using the latest in Web 2.0 technologies, personal genomics industries emphasize collaborative learning, consumer control, and unlimited access to one's genetic information. Whilst personal genomics and the new social media seem like disparate projects they share an important conceptual framework: one that conceives of bodies, subjectivities, and identities in terms of networks.

In this essay, I argue that the rise of personal genomics is technologically, economically, and most importantly, discursively tied to the rise of network subjectivity, an imperative of which is an understanding of self as always already a subject in the network. Through a theoretical and discursive analysis of the 23 andMe services and user-generated content I illustrate how personal genomics takes full advantage of social media technology and network subjectivity to advertise a new way of doing research that emphasizes collaboration between researchers and its members. Therefore, personal genomics discursively positions itself within social-networking culture that emphasizes continuous and constant sharing of oneself with others. I examine what is at stake in the company's claim of a new and collaborative scientific research model that fully utilizes Internet-based community building and resource sharing as well as 23andMe's 
stipulation that its services will democratize genomic research and empower participants. I argue that personal genomic services' position that sharing genetic information is good for everyone is grounded in a larger theoretical and practical notion that life in the network society requires of its denizens a constant contribution to the growth of the network. Sharing one's genetic information is considered to be an act of citizenship, precisely because it is good for the network - in other words, it enables a fast and expansive network growth. Here members are encouraged to think of themselves as dividuals, or nodes, in the network. Their actions acquire value based on network imperative to grow. Therefore, citizen bioscience is intricately tied, both in discourse and practices, to network growth and expansion.

\section{Genomics and network subjectivity}

The rise of personal genomics - and its use of citizen bioscience - is technologically, economically, and most importantly, discursively tied to the rise of a network society and, with it, a system of power relations necessitated by the rise of globalization and the emergence of information technology. ${ }^{6}$ Manuel Castells argued that network society is characterized by the pre-eminence of social morphology - a society formed around network structures. The logic of network societies privilege network form, expansion, and information flows over any particular social interest - a prioritization of the power of flows over the flows of power. ${ }^{7}$ Network power is a non-linear power relation, which operates through decentralized relations of sociability. This does not mean that network power is democratic - as David Singh Grewal argues, "in this case, aggregate outcomes emerge not from an act of collective decisionmaking, but through the accumulation of decentralized, individual decisions that, taken together, nonetheless conduce to a circumstances that affects the entire group" ${ }^{\text {" }}$ - but rather that it is a diffuse system of control and regulation operating through multitude of nodes. Singh Grewal defines network power as a complex system of coordination and expansion:

First, that coordinating standards are more valuable when greater numbers of people use them, and second, that this dynamic - which I describe as a form of power - can lead to the progressive elimination of the alternatives over which otherwise free choice can effectively be exercised.... when these ideas are considered together, the central premise of network power is that the benefits that come from using one standard rather than another increase with the number of users, such that dominant standard can edge out rival ones. ${ }^{9}$

Network power operates through decentralized relations of sociability, and as such it is always relational, always circumstantial, and always mutable. It also encourages relations of sociability in order to facilitate expansion. As Michael Hardt and Antonio Negri argue, "network power must be distinguished from other purely expansionist and imperialist forms of expansion. The fundamental difference is that the expansiveness of the immanent concept of sovereignty is inclusive, not exclusive. In other words, when it expands, this new sovereignty does not annex or destroy the other powers it faces but on the contrary opens itself to them, including them in the network."10 The power of the network is in its continuous and constant growth and openness to divergence and difference. ${ }^{11}$ This does not make the exercises of power benign; indeed network power operates through incorporation of dividend elements. Nothing can or should be outside of the network. ${ }^{12}$ And as such network power is embedded in what has been called a larger "control society."

In his essay The Postscript on Control Societies, Giles Deleuze argues that control societies are taking over disciplinary societies. Whereas disciplines operated through institutional confinement that aimed to mold individual bodies, controls are modulations changing from one moment to the next. This is a transition from power that acts on the body, to "the ultrarapid forms of apparently free-floating control." "13 Deleuze writes, "control is short-term and rapidly shifting, but at the same time continuous and unbounded, whereas discipline was long-term, infinite, and discontinuous. A man is no longer a man confined but a man in debt." 14 Control societies can be best understood in terms of networks, where individuals, or "dividuals" as Deleuze calls those living in control societies, are never done, never finish anything - but are continuously moved from one node to another.

In the control society, you are your information. As Deleuze points out " the digital language of control is made up codes indicating whether access to some information should be allowed or denied. We are no longer dealing with a duality of mass and individual. Individuals become "dividuals," and masses 
become samples, data, markets, or "banks."15 Identity constituted by information is identity in-flux. It can always be changed and altered. More importantly it can only be understood in the context of other data. This "surveillant assemblage" as Haggerty and Ericson call it, "operates by abstracting human bodies from their territorial settings and separating them into a series of discrete flows. These flows are then reassembled into distinct 'data doubles' which can be scrutinized and targeted for intervention." "The abstraction of self into data means that dividuals can understand their data, and therefore themselves, only in terms of relationship to others in the network. I argue that network subjectivity is the imperative of an information-based control society: subjectivity implies an understanding of self as always already a subject in the network. Network subjectivity grounds dividual identities in the relational aspect of the network, where the self is always connected and managed as a part of the network. Dividual identities and bodies function based on the principle of network power: rule through decentralized relations of sociability. As Galloway and Thacker write:

Control in the networks operates less through the exception of individuals, groups, or institutions and more through the exceptional quality of networks or of their topologies. What matters, then, is less the character of the individual nodes that the topological space within which and through which they operate as nodes. To be a node is not solely a casual affair; it is not to "do" this or to "do" that. To be a node is to exist inseparably from a set of possibilities and parameters - to function within a topology of control. ${ }^{17}$

I argue here that genomics is a product of control societies and as such it expatiates the functioning of information systems. It is dedicated to the collection, distribution, and circulation of information about life itself; its project is to generate more information. Moreover, the genomic body is constructed as the very definition of a dividual. It is a fragmented and fractured entity - a subject for "database" information searches, an entity to be classified, and categorized. As Terranova argues, "the cultural politics of information does not address so much the threat of 'disembodiment', or the disappearance of the body, but its microdissection and modulation, as it is split and decomposed into segments of variable and adjustable sizes (race, gender, sexual preferences; but also income, demographics, cultural preferences and interests)." 18 Therefore genomics functions according to network subjectivity; the purpose is to produce dividual identities that exist as nodes in the larger network.

23andMe emerges in this context. A child of genomic research and Web 2.0 technology, personal genomics exemplifies both contexts and proudly introduces the new model of research: Research 2.0. Personal genomics, and specifically 23 andMe, actively creates, promote, and sell citizen bioscience: a community building research initiative that promises to put individuals in control of their - in this case genetic data and provide greater ability to affect scientific research. From an activist standpoint, citizen bioscience enables its members to participate in scientific research decisions and can affect public policy. However, corporations can also appropriate citizen bioscience. I argue here that 23 andMe introduce a particular notion of citizen bioscience - one that promises freedom from institutional power through corporation-enabled control over one's genetic information. Therefore, citizen bioscience cannot be simply understood as a power-challenging initiative, but rather as a movement firmly embedded in relations of network power and control. It is important to critically examine how citizen bioscience - and social media technology that enables it - participates and contributes in network society. In the next section I examine how 23 andMe service is discursively tied to social media technology and network subjectivity.

\section{3andMe services and social media technology}

In January 2008, CBS Nightly News filed a report from an Internet start-up launch party. Hosted in the center of the Silicon Valley, Mountain View, California, the world watched as guests spit into beaker shaped tubes collected by the start-up's employees. While not the only personal genomics firm on the market - Navigenics, KNOME, and Decode companies provide similar services - 23andMe has shot to fame arguably due to its relationship with Google. ${ }^{19}$ The relationship is familial - a co-founder of 23anMe Anne Wojcicki is married to co-founder of Google Sergey Brin; professional - Google reportedly invested $\$ 3.9$ million in the start-up, ${ }^{20}$ and conceptual - as CBS News states, "23andMe aims to do for genetics what Google did for the Internet: make it easy and accessible for those curious about their DNA." 21 As Times describes, 23 andMe attempts to "Google your genes." 22 In other words, access to 
your personal genomic information is part of the larger move toward personal information systems. Enabled by increasingly cheaper genome sequencing technology, 23andMe genotypes your saliva-based DNA sample for $\$ 399 .{ }^{23}$ As such, it is the cheapest consumer personal genomic service on the market. The price dropped significantly in September 2009 as the service proclaimed that it has taken a step towards democratizing genetic information. ${ }^{24}$ And in the summer 2009 they launched a $\$ 99$ special to promote a "Research Revolution" initiative.

Discursively 23 andMe is tied to network subjectivity that promotes active engagement in the network. Equipped with the slogan "genetics just got personal," the company asserts that the service works largely as a genetic Facebook: it promises that you can get to know your friends and family through genetics; add some excitement to family reunions; make connections with DNA, and share as much or as little as you want. ${ }^{25} 23$ andMe also promises a global connectivity. The website says "by connecting you to others, we can also help put your genome into the larger context of human commonality and diversity." ${ }^{26}$ In fact, the company's expressed goal is to recruit virtual research populations to provide fodder for more genomic research. Through its four components - health and traits, family inheritance, ancestry, and 23 andWe -23 andMe collects genetic information, and in the process recruits their users to participate in its network of scientific data gathering and research.

The Family and Friends service specifically establishes the social-networking aspect of 23 andMe. It allows users to compare genes with family and friends and establishes a spectral and topographical relationality with others in the social network. Users can track the inheritance of specific genes, see what parts of their parents' DNA they share and compare genetic similarities with friends, family, and dead celebrities including Marie-Antoinette and Ben Franklin. The service uses a social networking model to emphasize that sharing one's genetic information does not have to be fraught with danger or abuse instead it can be easy, entertaining, and beneficial. What some are calling a "zygotic social networking" supposes that genetic information is just as valid a basis of social networking as friendship, college affiliation, business connection, or music interests. ${ }^{27}$ In the process, genomic research is represented as accessible, understandable, and manageable. 23andMe takes advantage of a new culture ushered in by Facebook, Twitter, and YouTube: a culture of constant and continuous sharing of yourself with the world. This network subjectivity constructs the self as a source of constant stream of information to be shared with others in the network. The self becomes a node in the network as it parcels through the cyberspace bits of information. Identity is inscribed in codes circulated through control society. Here, once more, dividual identity - understood in Deleuze's context of control society - situates itself because of network subjectivity. The network contextualizes information and gives it meaning.

23 andWe takes full advantage of Web 2.0 technology and citizen bioscience. The company advertises 23 andWe as a new way of doing research that emphasizes collaboration between researchers and 23andWe members. Billed as a Research 2.0 model, the company discursively positions itself within social-networking culture that, as we have argued above, emphasizes continuous and constant sharing of oneself with others. The website states:

At 23 andMe we envision a future in which people can use their genetic information to guide important decisions about health care and other aspects of their lives. 23andWe is our way of helping make that vision a reality, through a new kind of research that has the potential to produce valuable insights more quickly and less expensively than traditional methods. We call it Research 2.0, because this new approach lets you initiate, advise and participate in research via the Internet.

The company likewise advertises 23 andWe to the scientific community as a new way of doing research:

23 andWe intends to create another kind of collaboration. By connecting consenting 23andMe users who are interested in participating in research - and their genotype data - with the research community, we eliminate the need for inefficient recruitment procedures and distribute the cost of genotyping. We believe connecting people with scientists empowers everyone to accelerate the pace of research. ${ }^{29}$

Discursively, Research 2.0 explicitly connects genomics with new media technologies and Web 2.0 social-networking trends. 23andMe introduces Research 2.0 as a new and collaborative scientific research model that fully utilizes Internet-based community building and resource sharing. It stipulates that participation in the 23 andWe service will democratize genomic research and empower participants. Here 
members are encouraged to think of themselves as dividuals, or nodes, in the network and their actions acquire value based on that imperative. User-led research constructs a new type of biocitizen - one who actively uses social media to share and participate in research initiatives, generate and promote data. Here I argue that citizenship is exercised through participation in the network. Sharing one's genetic information is considered to be an act of citizenship, precisely because it is good for the network; here network becomes a substitute for a nation-state - an old beneficiary of citizenship. However, if network subjectivity allows for citizen bioscience to claim equal or democratic access to scientific research and data, it is important to understand how processes of exclusion work in the democratic narrative of citizen bioscience. These are the power relations that often obscured in the network society.

\section{Personal genomics and citizen bioscience}

Biological citizenship has been used in literature to describe an effort by active citizens to recuperate power away from medical and scientific institutions through bottom-up activism and the political economy of hope. Nikolas Rose and Carlos Novas term "biological citizenship": "all those citizenship projects that have linked their conceptions of citizens to beliefs about the biological existence of human beings, as individuals, as families and lineages, as communities, as population and races, and as a species. ${ }^{, 30}$ It operates within the political economy of hope: a social, political and economic system that advances the view of biology as mutable, changeable, and manipulable. Rose and Novas argue that - as tool of active biocitizens fighting against injustices and sufferings inflicted by medical, political, and economic establishments and institutions - the political economy of hope requires an active stance towards the future. Rose and Novas represent economy of hope and active biocitizenship as largely incorruptible enterprises that nobly resist institutional imposition of discipline and power. They describe communities forming on the Web and outside it as “moral pioneers - we would prefer to say 'ethical pioneers' - of a new kind of active biomedical citizenship. They are pioneering a new informed ethics of the self - a set of techniques for managing everyday life in relation to a condition, and in relation to expert knowledge. ${ }^{31}$ However, I argue that the question of power must be put at the center of any analysis of biocitizenship.

In fact, life in control society makes it necessary to theorize a new type of biocitizenship. Here citizenship is enacted as a participation in consumer behavior in the network society. No longer beholden to the interests of the nation-state, citizenship in control society is measure through the participation in the network. ${ }^{32}$ As a product of social media and network subjectivity citizen bioscience is fully aware of the value of information in control societies; its participants know that information makes the network function. Whereas biological citizens are reluctant to share their information, participants in citizen bioscience, trained through social-networking technologies and network subjectivity, are eager to do so. Their citizen duty is to increase the capacity of the network. In other words, citizen bioscience is a product of an unique economic system made possible by a simultaneously emergence of a free market economy, which conceives of an individual as "free" to sell access to their biological information, greater general accessibility to scientific research, and new media technologies that allow for faster, easier and increasingly cheaper access to biosocial communities. Therefore, whereas biological citizenship operates through political economy of hope, citizen bioscience is embedded in the "free labor" economy of network society. As Tiziana Terranova argues, "the end of factory has spelled out the marginalization of the old working class, but it has also produced generations of workers who have been repeatedly addressed as active consumers of meaningful commodities. Free labour is the moment where this knowledgeable consumption of culture is translated into excess productive activities that are pleasurably embraced and at the same time often shamelessly exploited." ${ }^{33}$ Biology is not only mutable, changeable, and manipulable - it is also utterly consumable. Biological information, as it flows through the network, thus becomes the most valuable of commodities: one that guarantees freedom from disciplinary institutions through full participation in the control society.

This logic is embraced by 23 andMe, whose core values include these statements: "we believe that having the means to access one's genetic information is good; we believe that your genetic information should be controlled by you, and we believe that the value of your genetic information will increase over time." ${ }^{34}$ Nature, in its review of consumer genomics, argues "although the locus of control of clinically relevant genetic information always will tilt toward clinicians, with the advent of consumer genomics the locus of the information generated lies squarely in the hands of individual clients rather than in the institutional formulation." In other words, freedom from disciplinary power imposed through its 
institutions can be achieved through the growth of the network and the subsequent increase in flows of information through dividual nodes. Or as Mr. Soicescu, a biotechnology entrepreneur said in an interview with the New York Times, "I'd rather spend my money on my genome than a Bentley or an airplane." He will check discoveries about genetic disease risk against his genome sequence daily, "like a stock portfolio." 35 As one's genome becomes a commodity, much as a car or an airplane, the consumer imperative to "own" his or her genome is construed as an exercise of citizen right. For example, one influential personal genome blog decries, "freedom to explore one's own biology, all the way down to the molecular level, should be among the freedoms we hold dear as individuals." 36 I argue that these declaratives should not be positioned as simply an issue of privacy debates or as evidence of the "new eugenics." Rather what is at stake in these services and their interpretations is the nature of network power. Citizen bioscience and personal genomics services can help us understand how material and immaterial subjectivities will be conceptualized as network imperatives. Moreover, it draws attention to discursive exclusions, as well as inclusions, in the democratic potential of citizen bioscience.

The illusion that participation in the network will somehow guarantee freedom from institutional power is at the heart of assumptions made about citizen bioscience. As I have argued above, these are the claims that position 23andMe as the product of network society. 23andMe Research Revolution definitely embraces these claims of freedom and democracy for all - a "Do-It-Yourself Revolution in Disease Research":

\begin{abstract}
This summer 23andMe is launching the Research Revolution, a community outreach program that empowers people to drive the direction of genetic research. This program is an opportunity for you to support disease research and positively influence the way it is funded and conducted. We pledge to do research on any disease that enrolls enough patients to ensure a productive study. The research will be conducted by 23 andMe scientists, working with outside researchers who have expertise in the particular topics being studied. Our research also requires data from control individuals who have not been diagnosed with the diseases we're studying. So every person - patient or control who enrolls in the program will receive a vote to cast for the disease they support. The disease that earns the most supporters by the end of the program will be studied first. By enrolling, you receive access to your own genetic data, including analysis of over 100 diseases and traits. This specially priced Research Edition of the 23 andMe service costs $\$ 99 .^{37}$
\end{abstract}

The testimonial videos on 23andMe home page also speak to the democratic potential of citizen bioscience. In them, 23 andMe members testify how the service affords them greater control over their lives and health. Their overarching message is that you have to be a number one advocate for your own health and that 23andMe enables its members to affect health outcomes not only in their lives, but in the larger research world as well. However, it is hard not to notice that most of 23andMe members - at least those who are active on the website - are white upper-middle class professionals. The assumption of the service is, of course, that since the entire population is $99 \%$ genetically alike, racial or class categories do not necessarily matter. However, I argue that it is socially and culturally important to be aware of how - at least discursively - 23andMe members become stand-ins for entire populations. Moreover, politically, there is much at stake in assumptions that research findings can be applied equally to all subjects and that results derived from one group can be applied to another. ${ }^{38}$ Here the rhetoric of equality goes along the rhetoric of "democratization" of the genome, employed by 23 andMe. A part of this rhetoric is an unquestioned assumption that access to one's genetic information automatically leads to "democratization" of the genome. This articulation of power of access in the network society makes citizen bioscience a tool of consumer-based, individual-level changes as supposed to a voice for a wider, public interest. Moreover, the rhetoric of equality present in narratives about "democratization" of genome assumes that access to information, on individual level, leads to social or public equality. It is perhaps needless to remind that this is not the case. A more fruitful theoretical investigation of this point is needed to fully understand how citizen bioscience becomes a functioning of network power in control society.

\title{
Conclusion
}

In her work, Danah Boyd argues that cultural elucidations about democratizing power of social networks often ignore how preexisting categories of class, race, and gender manifest themselves in these networks. ${ }^{39}$ In fact, more often than not, networks do not dissolve social power struggles, but rather obscure them. In this article, I have argued that the functioning of network power obscures how personal 
genomics construct and use citizen bioscience. This is due to individualizing effect that networks have on identities and subjectivities of its participants. As shown above, if network subjectivity is conceived in terms of dividual bodies and identities, then each body - reduced to its information - can be abstracted from its social and cultural context. It becomes, in a sense, a free-floating signifier. Any one node in the network can be substituted or replaced by any other node - it is that free-floating form of control that makes networks so resilient and adaptive to change. However, in biomedical discourse, it also means that any one body's scientific information can be a stand-in for the entire population. It is that assumption that inspired 23 andMe - and other personal genomic services - to promote and encourage citizen bioscience. Through its use of social media technologies and discourses 23andMe facilitates an active biocitizen engagement with genomic research and development. And while these engagements are presented as narratives of control, freedom, and empowerment, this article argued that, in this case, citizen bioscience is enveloped in "free labor" economy of the network society. As such, citizen bioscience functions to grow and expand network power. This is a fundamental tension that exists between positive changes that citizen bioscience can enact and the way that citizen bioscience is used at the service of network growth and expansion. This tension needs to be examined to begin a conversation about how citizen bioscience can be best implemented in years to come. After all, any democratic engagement with science needs to be aware of the social and cultural costs of scientific research.

\section{Notes and references}

1 The author would like to thank Rina Bliss for her review of the manuscript and for providing the data archive. A note of gratitude is also due to anonymous reviewers. Their thoughtful comments helped to make this a much better work.

2 23andMe official Web site, http://www.23andme.com (accessed October 30, 2008).

3 J. Kaiser, "Breakthrough of the Year: It's All About Me," Science Magazine 318, no.5858 (December 21, 2007$)$ : 1843, http://www.sciencemag.org/cgi/content/full/318/5858/1843.

4 The 7th Annual Year in Ideas, The New York Times, (December 9, 2007),

http:/query.nytimes.com/gst/fullpage.html?res=9B05EFDA1730F93AA35751C1A9619C8B63\&sec=\&spon=\&pagewanted=6; CBS Evening News, Searching for Answers in DNA, (January 16, 2008),

http://www.cbsnews.com/stories/2008/01/30/eveningnews/main3773346.shtml, (accessed August 20, 2008);

M. Schulman, Double Helix Dept.: Ptooey!, The NewYorker, (September 22, 2008),

http://www.newyorker.com/talk/2008/09/22/080922ta_talk_schulman;

T. Goetz, 23andMe will Decode your DNA for \$1,000. Welcome to the Age of Genomics, Wired Magazine, no. 15.12 (November 1, 2007).

5 Tim O'Reilly coined the term Web 2.0, which he defined as "the business revolution in the computer industry caused by the move to the internet as platform, and an attempt to understand the rules for success on that new platform. Chief among those rules is this: Build applications that harness network effects to get better the more people use them." It is now widely used to describe the use of the web as an interactive network platform. O'Reilly Radar Blog site, December 10, 2006, http://radar.oreilly.com/archives/2006/ 12/web-20-compact-definition-tryi.html, (accessed October 30, 2008).

${ }^{6}$ M. Castells (2000), The Rise of the Network Society. 2 ed. vol. 1, of The Information Age: Economy, Society and Culture, Oxford, Blackwell Publications (2000); M. Hardt and A. Negri (2000), Empire, Cambridge, Harvard University Press.

7 The Rise of the Network Society.

8 D. Singh Grewal (2008), Network Power: The Social Dynamics of Globalization, New Haven: Yale University Press, 9.

9 Network Power, 4.

${ }^{10}$ The Empire, 166.

${ }^{11}$ T. Terranova (2004), Network Culture: Politics for Information Age, London, Pluto Press.

12 A. Galloway and E. Thacker (2007), The Exploit: A Theory of Networks, Minneapolis, University of Minnesota Press.

${ }^{13}$ G. Deleuze (1995), Negotiations, trns. Martin Joughin, New York, Columbia University Press, 178.

${ }^{14}$ Negotiations, 181.

${ }^{15}$ Negotiations, 180.

${ }^{16}$ K.D. Haggerty and R.V. Ericson (2000), The Surveillant Assemblage, British Journal of Sociology 51(4): 605-662.

${ }^{17}$ The Exploit, 40.

${ }^{18}$ Network Power, 34.

${ }^{19}$ These companies offer a different array of services for different prices. Take, for example, 23andMe and Navigenics. At its inception, for \$999, 23 andMe provided a reading of 600,000 genetic polymorphisms and their relation to 11 diseases and 4 traits. The 23 andMe service was designed to increasingly inform the consumer and maintain the consumer as an active participant in the community database. For $\$ 2500$ and $\$ 250$ per year thereafter, Navigenics provided a year's service that included a reading of nearly 2,000,000 polymorphisms and their relation to 18 diseases. They also offered genetic counsel, medical counsel and physician counsel. Today, 23andMe and Navigenics both provide personal health statistics on 23 traits (23andMe: 20 diseases and 3 traits; Navigenics 23 diseases). 23andMe also comments on 68 conditions whose origins are unresolved in the literature. Decode offers services similar to 23 andMe for $\$ 985$, while KNOME offers whole-genome sequencing for $\$ 350,000$. 
${ }^{20}$ M. Herper, Google's Genetic Start-Up, Forbes Magasizine, September 12, 2007, http://www.forbes.com/2007/09/12/genomicswojcicki-brin-biz-sci-cx_mh_0912_23andme.html.

${ }^{21}$ (CBS Evening News, 2008)

22 R. Blakely, Search engine aims to Google your genes, Times, London, May 242007 ,

http://technology.timesonline.co.uk/tol/news/tech_and_web/the_web/article1832165.ece.

23 "Joining 23 andMe is easy - simply log in to www. 23 andMe.com, read through the online consent form and purchase the service. Within a few days you'll receive a sample collection kit in the mail, with straightforward instructions on how to provide a sample. The kit includes a pre-paid, pre-addressed envelope into which you place the barcoded tube containing your saliva. Pop it into any FedEx drop-box and it arrives shortly at our contracted laboratory for processing. Upon receiving your sample, laboratory personnel will extract DNA from cells in your saliva. Your DNA is then processed on an Illumina ${ }^{\circledR}$ BeadChip, which reads more than 550,000 SNPs (single nucleotide polymorphisms) plus a custom- designed set that analyzes more than 30,000 additional SNPs, chosen by 23 andMe scientists for their scientific relevance. What this means is that the laboratory process reads nearly 600,000 specific points on your genome. An electronic data set is generated, encrypted and sent to 23andMe. Approximately 4-6 weeks after mailing back the sample, you will receive an email notification that your 23andMe genome profile is ready. Once logged in, you'll discover a whole new world of you." (23andMe official Web site, accessed September 17, 2008). The company also provides free access to a demo account that takes visitors through the genome of Gregor Mendel and his family.

24 "It has always been our goal to democratize genetic information by giving individuals access to their DNA. We are proud to announce another step toward that goal with the introduction of v2, our next-generation analytical platform, at the new price of \$399. With v2 our customers will have access to an even more powerful set of SNPs to probe their unique genetic composition. And thanks to advances by Illumina, the provider of our genetic analysis technology, we are able to give you more information at a lower cost By making genetic data more affordable and accessible, we hope this development will spur the evolution of personal genomics as a potent force not just in science but also in medicine and everyday life." (23andMe official Web site, accessed September 17,2008).

${ }^{25} 23$ andMe official Web site, "How it works: sharing and community" section, https://www.23andme.com/community/ (accessed August 20, 2008).

${ }^{26}$ (Rhys Blakely 2007)

${ }^{27}$ ("The 7th Annual Year in Ideas," 2007)

${ }^{28} 23$ andMe official Web site, “About” section, https://www.23andme.com/you/23andwe/about/ (accessed September 17, 2008).

${ }^{29}$ Of course there are functional problematics with 23 andWe service. It is not clear whether scientific and medical community will want to work with a for-profit, Google-sponsored corporation. Right now 23 andWe has partnered with the Parkinson's Institute of Sunnyvale, CA, but this is the only partnership that has been announced. There is also a question of numbers; in order for the service to yield results it will need to provide a large number of participants. The drop in price is probably an attempt to circumvent that last issue.

${ }^{30}$ N. Rose and C. Novas (2005), Biological Citizenship, in Global Assemblages: Technology, Politics, and Ethics as Anthropological Problems, ed. Aihwa Ong and Stephen J. Collier, Malden: Blackwell Publisher, pg. 439-63.

${ }^{31}$ Biological Citizenship, in Global Assemblages, 450.

${ }^{32}$ M. Levina (2009), Regulation and Discipline in the Genomic Age: A consideration of differences between genetic engineering and genomics, in A Foucault for the 21st Century: Governmentality, Biopolitics and Discipline in the New Millennium, ed. Sam Binkley and Jorge Capetillo, Cambridge: Cambridge Scholars Publishing, pg. 308-319.

${ }^{33}$ Network Culture, 78.

${ }^{34}$ S.E. Brenner (2007), Common Sense for Our Genomes, Nature 449: 783-784.

${ }^{35}$ A. Harmon (2008), Gene Map Becomes a Luxury Item, The New York Times, March 4, 2008,

http://www.nytimes.com/2008/03/04/health/research/04geno.html.

${ }^{36}$ Jason Bobe's blog site, Biocensorship for Biocentury?, July 8, 2008, http://thepersonalgenome.com/2008/07/biocensorshipforthe-biocentury (accessed October 30, 2008).

${ }^{37} 23$ andMe official Web site, Research Revolution section, https://www.23andme.com/researchrevolution/overview/ (accessed September 14, 2009).

${ }^{38}$ S. Epstein (2007), Inclusion: The Politics of Difference in Medical Research, Chicago, University of Chicago Press.

${ }^{39}$ D. Boyd (2007), Apophenia Blog Essay, "Viewing American class divisions through Facebook and MySpace", June 24, 2007, http://www.danah.org/papers/essays/ClassDivisions.html.

\section{Author}

Marina Levina is a faculty in the Media Studies Program at the University of California, Berkeley. Her research interests include cultural studies of science and technology, new media, and critical theory. She is a co-editor of Post-Global Network and Everyday Life (forthcoming from Peter Lang in 2010) and she is currently completing a manuscript titled Life as a Virus, Life as a Code: Biopolitics of Control over Posthuman Life. She can be best contacted via email at mlevina@berkeley.edu.

E-mail: mlevina@berkeley.edu.

How TO CITE: M. Levina, Googling your genes: personal genomics and the discourse of citizen bioscience in the network age, Jcom 09(01) (2010) A06. 